\title{
Peningkatan Strategi dan Metode Pembelajaran Guru PAI dalam Era Revolusi industri 4.0
}

\author{
${ }^{1}$ Muliatul Maghfiroh, ${ }^{2}$ Sri Nurhayati \\ Institut Agama Islam Negeri Madura, Jl. Raya Panglegur Km. 4 Pamekasan 69371 \\ ${ }^{1}$ mulia.maghfiroh@gmail.com, 2yaatiecie@gmail.com
}

\begin{abstract}
The globalization becomes the reason of this theme. This is the flow that cannot be banned to enter Indonesia. The modern development of technology and the starting of the industrial revolution era 4.0 which stressed the digital economy, artificial intelligence, big data, and the robotic system cannot be stopped anymore. Facing this challenge, the teaching and learning activities in school are forced to change, including forming qualified teachers for our future. As we know that a teacher has a big role in education, he is both a facilitator and a guide. These roles give a teacher a bigger responsibility not only to transfer knowledge but also to value teaching. He also needs to facilitate the students to be ready to face the industrial era by giving intensive guidance. Therefore, as teachers, we need to be more creative, selective, and active to accommodate all students' needs and be more sensitive to the students' psychological condition. A teacher is not only needed to be good in managing the class but also having good teaching skills, empowering learning sources, understanding students' emotions, and others. In this program, the facilitator will strengthen the teacher's skill in using various and updated methods so that it can be made as a reference for teachers of PAI in high school level.
\end{abstract}

Keywords: Strategy; PAI Teachers; Industry 4.0 Era

\section{Abstrak}

Pemilihan tema tersebut bermula dari arus globalisasi yang sudah tidak terbendung masuk ke Indonesia. Disertai dengan perkembangan teknologi yang semakin canggih, dunia kini memasuki era revolusi industri 4.0, yakni menekankan pada pola digital economy, artificial intelligence, big data, dan robotic. Menghadapi tantangan tersebut, pengajaran di sekolah pun dituntut untuk berubah, termasuk dalam menghasilkan guru berkualitas bagi generasi masa depan. Mengingat posisi pendidik yang sangat signifikan sebagai fasilitator dan pembimbing, maka dari sini sesungguhnya pendidik memiliki tugas yang lebih berat tidak hanya memegang fungsi transfer pengetahuan akan tetapi pendidik juga harus mampu menfasilitasi siswa dalam mengembangkan dirinya disertai dengan bimbingan yang intensif. Oleh karena itu pendidik dituntut untuk lebih kreatif, selektif, dan proaktif dalam mengakomodir kebutuhan siswa guru juga lebih peka terhadap karakteristik maupun psikis siswa. Guru bukan hanya dituntut untuk bisa menguasai teknik pengelolahan kelas, keterampilan, mengajar, pemanfaatan sumber belajar, penguasaan emosional siswa, penguasaan kondisi kelas dan sebagainya. Dalam pengabdian masyarakat ini akan dimantapkan penerapan metode pengajaran yang lebih bervariasi dan terkini sehingga bisa menjadi bahan referensi kepada guruguru PAl tingkat sekolah menengah pertama dalam mengajar.

Kata Kunci: Strategi; Guru PAI; Era Industri 4.0 


\section{Pendahuluan}

Arus globalisasi membawa manusia untuk bergantung sangat besar pada teknologi. Dampak positif dari teknologi sangat bisa dilihat oleh semua genarasi. Kecepatan serta kemudahan bekerja adalah satunya. Namun hendaknya kita bisa arif dan bijaksana dalam menerima segala kemudahan ini karena sudah tentu dampak positif ini pasti disertai dengan dampak negatif yang mengikuti. Peran manusia akan lambat laun tergantikan oleh teknologi yang tanpa kita bawa dalam kehidupan kita.

Arus globalisasi sudah tidak terbendung masuk ke Indonesia. Disertai dengan perkembangan teknologi yang semakin canggih, dunia kini memasuki era revolusi industri 4.0, yakni menekankan pada pola digital economy, artificial intelligence, big data, robotic, dan lain sebagainya atau dikenal dengan fenomena disruptive innovation. Menghadapi tantangan tersebut, pengajaran di sekolah pun dituntut untuk berubah, termasuk dalam menghasilkan guru berkualitas bagi generasi masa depan. Perubahan dalam bidang sumber daya sangat penting, meliputi pengembangan kapasitas guru dan tutor dalam pembelajaran. Jadi guru ini perannya juga sebagai tutor.

Pada era ini guru PAI memiliki tuntutan lebih, baik dalam kompetensi maupun kemampuan untuk melakukan inovasi pembelajaran. Kondisi guru PAl saat ini sendiri masih didominasi oleh generasi baby boomers dan generasi $\mathrm{X}$ yang merupakan digital immigrant. Sementara siswa yang dihadapi merupakan generasi millennial atau digital native. Jika guru PAI abai dalam penguasaan teknologi, tidak kreatif, dan inovatif, maka guru akan bisa digantikan teknologi. Maka guru PAI selain melek literasi digital juga menempatkan diri sebagai motivator dan inspirator. Oleh sebab itu semakin berkembangnya pendidikan di Era Revolusi 4.0 maka guru PAI harus berpacu meningkatkan startegi dan metode pembelajarannya di sekolah maupun di luar sekolah.

Pada dasarnya pendidikan Islam menekankan pada "bimbingan" bukan "pengajaran" yang mengandung konotasi otoritatif pihak pelaksana pendidikan, katakanlah calon pendidik, dengan bimbingan sesuai dengan ajaran-ajaran Islam, maka anak didik mempunyai ruang gerak yang cukup luas mengaktualisasikan segala potensi yang di milikinya. Disini pendidik, berfungsi sebagai "fasilitator" penunjuk jalan kearah penggalian potensi anak didik, dengan demikian pendidik bukanlah segala-galanya, sehingga guru cenderung menganggap anak didik bukan apa-apa, selain manusia yang kosong yang perlu di isi. Dengan kerangka dasar pengertian ini, maka pendidik menghormati anak didik sebagai individu yang memilliki berbagai potensi, Dari kerangka pengertian dan hubungan antara peserta didik dengan pendidik, dapat pula sekaligus dihindari, apa yang disebut "Bangking concep" dalam pendidikan yang banyak dikritik dewasa ini. Penerapan semacam ini yang dicoba inquiri.

Pendidikan Islam dalam era revolusi industri 4.0 ini menghadapi tantangan terutama moral sosial yaitu kegiatan penataan kehidupan yang paling baik yang seharusnya dialami oleh generasi muda agar mampu menghadapi masa depan dengan integritas (kesatuan) yang tangguh. Untuk 
itu maka Pendidikan Islam diharapkan mampu menyusun pola pikir yang sistematis untuk membina pribadi muslim yang kreatif dan berintegritas tinggi, sehingga mampu menyesuaikan diri dengan perubahan yang terjadi di masyarakat. Dengan demikian maka pendidikan Islam dapat mengajarkan moral positif yang berakar pada nilai-nilai Islami, sebagai pendorong moral reasoning atau penalaran akhlak yang sangat dibutuhkan untuk menentukan pilihan dan keputusan tentang masalah-masalah baru yang muncul dalam proses pembangunan ini.

Keberhasilan proses belajar mengajar dalam rangka mewujudkan tujuan pendidikan sangat dipengaruhi oleh banyak faktor. Baik itu secara teknis maupun nonteknis. Tidak hanya pendidik dan murid yang berperan dalam keberhasilan pendidikan akan tetapi lebih dari itu juga harus ditunjang aspek lain.Salah satu aspek yang sangat penting dalam rangka mencapai tujuan pendidikan adalah metode.

Seorang pendidik perlu mengetahui sekaligus mengusai berbagai metode dan strategi belajar mengajar yang digunakan dalam kegiatan belajar mengajar. Mengingat posisi pendidik yang sangat signifikan dengan pendidikan sebagai fasilitator dan pembimbing, maka dari sini sesungguhnya pendidik memiliki tugas yang lebih berat tidak hanya memegang fungsi transfer pengetahuan akan tetapi lebih dari itu pendidik harus mampu menfasilitasi siswa dalam mengembangkan dirinya disertai dengan bimbingan yang intensif. Oleh karena itu pendidik dituntut untuk lebih kreatif, selektif dan proaktif dalam mengakomodir kebutuhan siswa guru juga lebih peka terhadap karakteristik maupun psikis siswa. Beberapa usaha yang dapat dilakukan guru dalam rangka menciptakan kondisi yang efektif dan kondusif adalah kecekataan dalam memilih sebuah metode dengan pendekatan emosional dan psikologis siswa untuk itu seorang guru bukan hanya dituntut untuk bisa menguasai teknik pengelolahan kelas, keterampilan, mengajar, pemanfaatan sumber belajar, penguasaan emosional siswa, penguasaan kondisi kelas dan sebagainya.

Berangkat dari pemikiran tersebut, maka Prodi Pendidikan Agama Islam (PAI) Fakultas Tarbiyah IAIN Madura bermaksud mengadakan Pengabdian Kepada Masyarakat (PKM) workshop "Peningkatan Strategi dan Metode Pembelajaran Guru PAI dalam era Revolusi industri 4.0 " serta diikuti oleh Penandatanganan MoU antara Program Studi PAI Fakultas Tarbiyah IAIN Madura dengan MGMP PAI tingkat SMP Kabupaten Pamekasan. Harapan dari acara ini adalah seluruh pengurus dan anggota MGMP PAI tingkat SMP Kabupaten Pamekasan mengetahui dan mengimplementasikan aneka inovasi strategi dan metode Pembelajaran PAI di Era Revolusi industri ini dengan maksimal.

\section{Metode}

Tempat dan sasaran pengabdian masyarakat yang dilaksanakan oleh program studi Pendidikan Agama Islam (PAI) pada mulanya adalah guru guru pendidikan agama islam se-kecamatan Tlanakan, Pamekasan. Namun setelah survey lokasi pada tanggal 22 Juli 2019 ke SMPN I Tlanakan, wakil 
kepala Sekolah yaitu Bapak Slamet menyampaikan bahwa di Kecamatan Tlanakan hanya terdapat 2 guru PAI, 1 di SMPN I Tlanakan dan 1 lagi di SMP Swasta. Disamping itu pula guru PAI yang berada di SMPN I Tlanakan sedang melaksanakan ibadah Haji. Hal itu dianggap tidak memungkinkan bagi program studi PA untuk melaksanakan pengabdian kepada masyarakat di kecamatan Tlanakan. sehingga ketua PKM Program Studi PAI melakukan pendekatan kepada Ketua MGMP (Musyawarah Guru Mata Pelajaran) Pendidikan Agama Islam tingkat SMP Kabupaten Pamekasan pada hari selasa 23 Juli 2019 di SMPN II Larangan. Pertemuan tersebut menyepakati bahwa MGMP PAI tingkat SMP Kabupaten Pamekasan menyambut dengan tangan terbuka pelaksanaan Pengabdian Kepada Masyarakat oleh Program Studi PAI dengan sasaran adalah Seluruh pengurus dan anggota MGMP PAI tingkat SMP Se Kabupaten Pamekasan. Disamping itupula Kaprodi PAI menawarkan kerjasama berupa penandatanganan MoU (Memorandum of Understanding) antara Program Studi PAI Fakultas Tarbiyah dengan MGMP PAI tingkat SMP Kabupaten Pamekasan, kerjasama tersebut dalam implementasi tri dharma perguruan tinggi dan ternyata hal itu juga disepakati oleh ketua MGMP PAI tingkat SMP yaitu Bapak Masudi, M.Pd.

Adapun Dasar Hukum kegiatan ini adalah:

a. Undang-Undang Nomor 20 Tahun 2003, tentang Sistem Pendidikan NasionalUndang-Undang Nomor 14 Tahun 2005 tentang Guru dan Dosen.

b. Undang-Undang Nomor 12 tahun 2012 tentang Pendidikan Tinggi.

c. Peraturan Pemerintah Nomor 19 Tahun 2005 tentang Standar Nasional Pendidikan sebagaimana telah diubah dengan Peraturan Pemerintah RI Nomor 32 Tahun 2013 tentang Perubahan atas Peraturan Pemerintah RI Nomor 19 Tahun 2005.

d. Peraturan Menteri Pendidikan dan Kebudayaan Republik Indonesia Nomor 49 Tahun 2014 Tentang Standar Nasional Pendidikan Tinggi.

e. Peraturan Pemerintah Nomor 74 Tahun 2008 tentang Guru.

f. Peraturan Pemerintah RI Nomor 37 Tahun 2009 tentang Dosen.

g. Peraturan Pemerintah RI Nomor 17 Tahun 2010 tentang Pengelolaan dan Penyelenggaraan Pendidikan sebagaimana telah diubah dengan Peraturan Pemerintah RI Nomor 66 Tahun 2010 tentang Perubahan atas Peraturan Pemerintah RI Nomor 17 Tahun 2010.

h. Peraturan Menteri Agama RI Nomor 34 Tahun 2019 tentang Organisasi dan Tata Kerja IAIN Madura (Berita Negara RI Tahun 2019 Nomor 1746);

i. Peraturan Menteri Keuangan RI Nomor 32/PMK.02/2018 tentang Standar Biaya Masukan Tahun Anggaran 2019.

j. Peraturan Menteri Agama RI Nomor 45 Tahun 2014 tentang Pejabat Perbendaharaan Negara pada Kementerian Agama (Berita Negara RI Tahun 2014 Nomor 1740).

k. Keputusan Menteri Agama RI Nomor 20 Tahun 2014 tentang Penunjukan Kuasa Pengguna Anggaran di Lingkungan Kementerian Agama. 
I. Keputusan Menteri Agama RI Nomor 230 Tahun 2013 tentang Pendelegasian Kewenangan Kepada Kepala Satuan Kerja untuk Mengangkat Bendahara Penerimaan dan Bendahara Pengeluaran di Lingkungan Kementerian Agama.

Pelaksanaan Program Pengabdian Kepada Masyarakat (PKM) workshop "Peningkatan Strategi dan Metode Pembelajaran Guru PAI dalam era Revolusi industri 4.0" dengan MGMP PAI tingkat SMP Kabupaten Pamekasan mempunyai manfaat bagi MGMP PAI tingkat SMP Kabupaten Pamekasan yaitu untuk pengembangan jaringan dan keilmuan karena dapat bekerja sama dengan Prodi PAI Fakultas Tarbiyah IAIN Madura serta melakukan kerjasama dalam bidang Tri Dharma Perguruan Tinggi. Sedangkan bagi Program Studi PAI Fakultas Tarbiyah, kegunaan pegabdian kepada masyarakat ini dapat menambah relasi dan jaringan tentang ke-PAlan, mendapatkan rekan untuk Tri Dharma Perguruan Tingg. Sedangkan bagi guru PAI sendiri pengabdian ini akan memfasilitasi guru agar mampu menyusun perencanaan pendidikan di Prodi PAI yang up to date sesuai dengan perkembangan zaman. Diharapkan guru mampu mengimplementasikan perencanaan pembelajaran sesuai kondisi Era Revolusi Industri 4.0. Bagi mahasiswa sendiri hal ini dapat mendewasakan mereka dengan menlengkapi mereka dengan kemampuan mengetahui aneka inovasi pembelajaran PAI yang ter-update dan mengimplementasikan pada saat PM2 dan saat terjun ke lembaga pendidikan.

Peserta Program workshop Pengabdian Kepada Masyarakat (PKM) workshop "Peningkatan Strategi dan Metode Pembelajaran Guru PAI dalam era Revolusi industri 4.0" yaitu Guru PAI dalam Organisasi MGMP PAI tingkat SMP se Kabupaten Pamekasan sejumlah 30, mahasiswa/l Program studi PAl lintas semester sejumlah 6 orang mahasiswa, dan Dosen Program studi Pendidikan Agama Islam (PAl) sebanyak 2 orang dosen.

Narasumber Program workshop Pengabdian Kepada Masyarakat (PKM) workshop "Peningkatan Strategi dan Metode Pembelajaran Guru PAI dalam era Revolusi industri 4.0" adalah Muliatul Maghfiroh, M.Pd.I dengan Moderator Sri Nurhayati, M.Pd.

Sedangkan program Pengabdian Kepada Masyarakat (PKM) ini workshop "Peningkatan Strategi dan Metode Pembelajaran Guru PAI dalam era Revolusi industri 4.0" dilaksanakan pada hari rabu tanggal 31 Juli 2019 bertempat di Laboratorium SMPN I Pamekasan.

Pelaksanaan kegiatan ini dilakukan dengan 2 sesi acara yaitu pertama dengan mengadakan workshop peningkatan strategi dan metode pembelajaran guru PAI dalam era revolusi industry 4.0. yang dipandu oleh ibu Sri Nurhayati dengan pemateri lbu Muliatul Maghfiroh, M.Pd.I. Pada sesi ini diperkenalkan semua macam metode pembelajaran yang berbasis daring. Pemateri memperkenalkan metode pembelajaran ini satu persatu dilengkapi dengan penjabaran kelebihan dan kekurangannya. Pada sesi ini peserta diberikan kesempatan untuk sharing dan bertanya seputar penggunaan straetegi dan metode yg diperkenakan oleh pemateri. 
Sesi kedua adalah sesi pendampingan pelatihan. Hal ini dilaksanakan dengan tujuan untuk menerapkan beberapa metode dan strategi yang telah dipaparkan pada sesi sebelumnya. Semua peserta dibagi menjadi 6 kelompok besar dengan 6 peserta dalam setiap kelompok. Setiap kelompok mendiskusikan satu strategi atau metode. Para peserta mendiskusikan design pembelajaran yang cocok untuk suatu metode dengan strategi tertentu. Peserta dalam satu kelompok juga mempersiapkan media yang akan digunakan, mereka menuangkannya dalam bentuk RPP.

Setelah kegiatan diskusi selesai, setiap kelompok menerapkan metode jigsaw dalam mempresentasikan apa yang telah mereka rencanakan dalam bentuk peer-teaching. Peserta juga mengulas kekurangan dan kelebihan metode dan strategi yang dipakai, menjawab pertanyaan dari kelompok lain. Setelah setiap kelompok mempresentasikan metode dan strategi yang dipakain, peserta dikembalikan pada kelompok semula kemudian setiap kelompok diminta untuk membuat kesimpulan dari hasil presentasi di kelompok lain.

\section{Hasil Kegiatan dan Pembahasan}

Adapun hasil kegiatan Pengabdian Kepada Masyarakat (PKM) workshop "Peningkatan Strategi dan Metode Pembelajaran Guru PAI dalam era Revolusi industri 4.0" dari paparan narasumber sebagai berikut:

Revolusi Industri yang pernah terjadi di dunia ini ada beberapa era yaitu revolusi industri 1.0, revolusi industri 2.0, revolusi industri 3.0 dan revolusi industri 4.0 yang menjadi pengisi penting di abad 21 . Revolusi ini memiliki enam belas keterampilan pokok. Keenam belas ini dibagi menjadi tiga bagian yaitu (1) literasi yang mendasar, (2) kompetensi dan (3) kualitas karakter. Tiga bagian ini sangat dibutuhkan untuk mengembangkan diri di abad 21 baik sebagai generasi milenial, media digital atau paradigm disrupsi.

Tantangan yang ada pada Revolusi industri 4.0 bagi Pendidikan agama Islam adalah big data, sales force, internet of things, additive manufacturing, simulation, augmented reality, sistem integrasi, dan automated robots. Disamping itu pula dampak positifnya adalah serasa dunia ada di genggaman kita, namun berdampak negative semakin maraknya perdaran narkoba, tawuran pelajar, seks bebas, LGBT dan fenomena-fenomena yang menggerus akhlakul karimah peserta didik akibat maraknya penggunaan teknologi yang disalah gunakan.

Oleh karena itu maka Perkembangan Pembelajaran Pendidikan Agama Islam harus mampu menjawab tantangan tersebut dengan melakukan berbagai macam inovasi strategi dan metode pembelajaran serta menggunakan campuran strategi maupun metode dengan perkembangan teknologi bagi generasi milenial.

Berbicara tentang strategi pembelajaran berasal dari pendekatan pembelajaran yang telah ditetapkan. Newman dan Logan (Abin Syamsuddin Makmun, 2003) mengemukakan empat unsur strategi dari setiap usaha, yaitu: 
a. Mengidentifikasi dan menetapkan spesifikasi dan kualifikasi hasil (output) dan sasaran (target) yang harus dicapai, dengan mempertimbangkan aspirasi dan selera masyarakat yang memerlukannya.

b. Mempertimbangkan dan memilih jalan pendekatan utama (basic way) yang paling efektif untuk mencapai sasaran.

c. Mempertimbangkan dan menetapkan langkah-langkah (steps) yang akan dtempuh sejak titik awal sampai dengan sasaran.

d. Mempertimbangkan dan menetapkan tolok ukur (criteria) dan patokan ukuran (standard) untuk mengukur dan menilai taraf keberhasilan (achievement) usaha.

Jika kita terapkan dalam konteks pembelajaran, keempat unsur tersebut adalah:

a. Menetapkan spesifikasi dan kualifikasi tujuan pembelajaran yakni perubahan profil perilaku dan pribadi peserta didik.

b. Mempertimbangkan dan memilih sistem pendekatan pembelajaran yang dipandang paling efektif.

c. Mempertimbangkan dan menetapkan langkah-langkah atau prosedur, metode dan teknik pembelajaran.

d. Menetapkan norma-norma dan batas minimum ukuran keberhasilan atau kriteria dan ukuran baku keberhasilan.

Strategi pembelajaran adalah suatu kegiatan pembelajaran yang harus dikerjakan guru dan siswa agar tujuan pembelajaran dapat dicapai secara efektif dan efisien. Dilihat dari strateginya, pembelajaran dapat dikelompokkan ke dalam dua bagian pula, yaitu: (1) exposition-discovery learning dan (2) group-individual. Ditinjau dari cara penyajian dan cara pengolahannya, strategi pembelajaran dapat dibedakan antara strategi pembelajaran induktif dan strategi pembelajaran deduktif. Strategi pembelajaran sifatnya masih konseptual dan untuk mengimplementasikannya digunakan berbagai metode pembelajaran tertentu. Dengan kata lain, strategi merupakan "a plan of operation achieving something" sedangkan metode adalah "a way in achieving something" Metode pembelajaran di sini dapat diartikan sebagai cara yang digunakan untuk mengimplementasikan rencana yang sudah disusun dalam bentuk kegiatan nyata dan praktis untuk mencapai tujuan pembelajaran. Terdapat beberapa metode pembelajaran yang dapat digunakan untuk mengimplementasikan strategi pembelajaran, diantaranya: (1) ceramah; (2) demonstrasi; (3) diskusi; (4) simulasi; (5) laboratorium; (6) pengalaman lapangan; (7) brainstorming; (8) debat, (9) simposium, dan sebagainya.

Adanya Revolusi Industri 4.0 maka solusi pembelajarn Pendidikan Agama Islam harus harus reorientasi kurikulum disesuaikan dengan kondisi peserta didik dan sarana prasarana yang ada disekolah. adapun tawaran dari narasumber untuk reorientasi kurikulum PAI di SMP yaitu:

a. Penilaian terintegrasi dengan proses.

b. Pembelajaran lebih kontekstual tidak hanya tekstual. 


\section{c. Digital literacy. \\ d. Proses pembelajaran mix dengan E-Learning. \\ e. Pembelajaran berbasis Hidden kurikulum.}

Pada kegiatan ini juga dijelaskan macam-macam pembelajaran menggunakan E-Learning baik menggunakan akan media sosial atau akun daring instalasi manual. Salah satu contoh E-Learning yang diajarkan adalah pembuatan akun Moodle. Moodle (Modular Object-Oriented Dynamic Learning Environment ) adalah software Learning Management System (LMS) atau sering disebut E-learning yang opensource, dapat diperoleh secara gratis. Moodle adalah sistem yang sangat lengkap dengan fitur-fitur yang banyak. Moodle sangat efektif untuk digunakan sebagai sarana pembelajaran di sekolah-sekolah dan universitas. Dengan moodle, guru dapat memberikan materi berupa teks, web, animasi, multimedia, ebook, presentasi, diskusi, ujian, dan belajar online.

Moodle dapat di install di berbagai macam Sistem Operasi, tetapi yang kita bahas disini adalah install di OS Windows, dengan pertimbangan pada umumnya Windows paling banyak di instal di Indonesia khususnya di lingkungan pendidikan. Moodle dapat difungsikan sebagai sistem offline, hanya dapat di akses di lingkungan LAN sekolah, atau sistem online, dapat diakses via internet. Kedua hal ini tergantung kepada ketersediaan bandwidth sekolah yang bersangkutan.

Selain dijelaskan dan dipraktekkan sedikit tenutang Moodle, narasumber mengajak seluruh peserta workshop untuk simulasi penggunaan multimedia dengan memadupadankan dengan metode marketplace atau metode outlet. Media yang digunakan adalah HP (Handphone) dengan membuka akun playstore serta menuliskan di pencarian materi/software apa saja yang dikehendaki oleh guru kemudian melakukan instalasi di HP guru. Materi tersebut yang digunakan media pembelajaran. kemudian penggunaan metode market place mengarahkan simulasi bahwa peserta dikondisikan menjadi 3 kelompok dengan materi yang berbeda kemudian setiap kelompok terdapat penjaga outlet serta juru bicaranya. Yang ditawarkan ke pengunjung adalah penjelasan terkait tema yang telah ditentukan oleh guru. Kemudian dengan hitungan 3 selain jubir dan penjaga outlet atau anggota kelompok bersama-sama mengunjungi outlet yang telah ditetapkan secara bergantian. setaip outlet dijelaskan materi yang tidak sama dengan menggunakan media software/aplikasi yang telah ada di HP penjaga outlet. para pengunjung diperkenankan untuk bertanya sesuai prosedur setiap outlet.

Untuk bahan evaluasi dapat dilihat seberapa aktif pengunjung outlet bertanya pada penjaga outlet serta ketika selesai simulasi maka guru mengacak siswa untuk menjelaskan apa yg ia pahami tentang materi-materi disetiap outlet yang ia kunjungi disamping penugasan lain oleh guru.

Hal yang perlu diperhatikan dalam pemilihan metode dan strategi yang tepat adalah kesesuaian metode dan strategi tersebut dengan umur peserta didik serta perkembangannya dalam pendidikan. Penggunaan internet 
dalam pembelajaran juga perlu diperhatikan semaksimal mungkin dampak positive serta negatifnya. Pengawasan guru disini sangatlah penting karena keragaman jenis dan corak pendidikan islam saat ini semakin banyak ditopang dengan kecanggihan yang menjadikan manusia mudah dalam mengakses informasi secara virtual melalui media sosial dan semacamnya. Manusia yang dinamis terus berevolusi sehingga dinamika persoalan dalam kehidupan bermasyarakat semakin kompleks dan rentan terjadinya konflik.(Sa'diyah \& Nurhayati, 2019: 181).

Untuk itu diperlukan pemahaman yang mumpuni dari seorang guru dalam memilih strategi dan metode yang benar sesuai dengan kemampuan peserta didik. Kesesuaian tersebut akan menciptakan suasana yangmenyenangkan dalam pembelajaran. Suasana yang menyenangkan akan meningkatkan motivasi peserta didik. Jika motivasi peserta didik tinggi maka tujuan pembelajaran akan cepat tercapai (Rusydiyah \& Praja, 2019: 154). Penggunaan internet sebagai strategy dalam pembelajaran sangatlah memungkinkan membuat peserta didik termotivasi karena pada jenjang Sekolah Menengah Pertama peserta didik cenderung menguasai pengguaan internet.

Dikatakan pengawasan guru sangatlah penting karena apapun bisa peserta didik pelajari dari internet, begitu juga pendidikan moral utamanya yang berkorelasi erat dengan implementasi nilai-nilai spiritualitas keberagamaan. Seorang guru berperan dalam fase Premoral (Preconventional) peserta didik. Pada tahapan ini semua perilaku dan sikap manusia lebih cenderung banyak dikontrol oleh implus biologis dan sosial. Fase dimana manusia dalam pertumbuhannya sangat bergantung pada kebutuhan primer dan perhatian lingkungan sekitar (Zaini \& Ramlan, 2019: 207). Jika dalam proses pembelajaran sang guru optimal dalam pemberian pengawasan maka peserta didik akan merasa mendapatkan perhatian dari lingkungan sekitarnya.

Kegiatan Pengabdian Kepada Masyarakat (PKM) workshop "Peningkatan Strategi dan Metode Pembelajaran Guru PAI dalam era Revolusi industri 4.0 " dapat dikatakan sukses terlaksana secara kondusif sesuai rencana yang berjumlah 40 orang dengan rincian Guru PAI dalam Organisasi MGMP PAI tingkat SMP se Kabupaten Pamekasan sejumlah 30, mahasiswa /I Program studi PAl lintas semester sejumlah 6, dan Dosen Prodi PAl sebanyak 2 orang atau bisa dikatakan kehadiran peserta $100 \%$ dan yang tidak hadir kosong.

\section{Penutup}

Berdasarkan paparan hasil Kegiatan Pengabdian Kepada Masyarakat (PKM) workshop "Peningkatan Strategi dan Metode Pembelajaran Guru PAI dalam era Revolusi industri 4.0" dan Penandatanganan MoU antara Program Studi PAI Fakultas Tarbiyah IAIN Madura dengan MGMP PAI tingkat SMP Kabupaten Pamekasan terlaksana secara efektif dan kondusif dengan dibuktikan antusiasnya peserta untuk mengikuti Kegiatan Pengabdian Kepada Masyarakat (PKM) workshop "Peningkatan Strategi 
dan Metode Pembelajaran Guru PAI dalam era Revolusi industri 4.0 " dan Penandatanganan MoU antara Program Studi PAI Fakultas Tarbiyah IAIN Madura dengan MGMP PAI tingkat SMP Kabupaten Pamekasan yang diselenggarakan oleh Program Studi Pendidikan Agama Islam.

Hasil kegiatan Pengabdian Kepada Masyarakat (PKM) workshop "Peningkatan Strategi dan Metode Pembelajaran Guru PAl dalam era Revolusi industri 4.0" dan Penandatanganan MoU antara Program Studi PAI Fakultas Tarbiyah IAIN Madura dengan MGMP PAI tingkat SMP Kabupaten Pamekasan karena dengan itu maka Para guru PAI di MGMP PAl tingkat SMP Kabupaten Pamekasan, Dosen, dan mahasiswa calon pendidik PAI mampu menciptakan aneka inovasi strategi pembelajaran dan aneka metode pembelajaran untuk matapelajaran PAl yang up-to date sesuai kondisi, lingkungan serta sarana prasarana yang ada.

Rekomendasi yang dapat disampaikan oleh fasilitator adalah pentingnya kegiatan workshop peningkatan kompetensi dosen dan mahasiswa dilaksanakan secara berkesinambungan di perguruan tinggi khususnya di Prodi Pendidikan Agama Islam. Perlunya pemahaman konsep dasar materi tentang inovasi dan strategi dan media pembelajaran PAI di Era Revolusi Industri 4.0. Perlunya pemahaman bagi mahasiswa tentang inovasi dan strategi dan media pembelajaran PAI di Era Revolusi Industri 4.0.

\section{Daftar Pustaka}

Azra, A., \& Zamhari. (2006). Mencetak Muslim Modern. Jakarta: Raja Grafindo Persada.

Baharuddin. (2007). Teori Belajar dan Pembelajaran. Yogyakarta: Ar Ruzz Media.

Haris, Abd., \& Sholehuddin. (2015). Inovasi Pendidikan dan Pembelajaran: Merajut Asa Pendidikan Islam di Tengah Kontestasi dalam Sistem Pendidikan Nasional. Surabaya: Imtiyas.

Otib, S. H. (2017). Materi Pokok Metode Pengembangan Moral dan Nilainilai Agama (7th ed.). Tangerang Selatan: Universitas Terbuka.

Rusydiyah, E. F., \& Praja, T. S. (2019). Joyful Learning in Fiqh Lesson Using Vlog: A Case Study at 26 Muhammadiyah Kalitengah Islamic Junior High School Lamongan. TADRIS: Jurnal Pendidikan Islam, 14(2), 147-160. doi: 10.19105/tjpi.v14i2.2750

Sa'diyah, H., \& Nurhayati, S. (2019). Pendidikan Perdamaian Perspektif Gus Dur: Kajian Filosofis Pemikiran Pendidikan Gus Dur. TADRIS: Jurnal Pendidikan Islam, 14(2), 175-188. doi: 10.19105/tjpi.v14i2.2759

Subanda, M. A. (2013). Psikologi Agama dan Kesehatan Mental (1st ed.). Yogyakarta: Pustaka Pelajar.

Zaini, Z., \& Ramlan, R. (2019). Penguatan Pendidikan Aqidah Anak dari Penyimpangan Budaya Online. TADRIS: Jurnal Pendidikan Islam, 14(2), 201-214. doi: 10.19105/tjpi.v14i2.2736. 